\title{
Impact of the foundation program and high school grade in predicting the cumulative grade point average (CGPA) among the graduates of the nursing program at the Ministry of Health Educational Institutes in
} Oman

\author{
Said A. Alghenaimi*1, Maiyasa G. Al-Saadi ${ }^{1}$, Hamed K. Al Reesi ${ }^{2}$ \\ ${ }^{1}$ Oman College of Health Sciences-South Batinah, Ministry of Health, Rustaq, Oman \\ ${ }^{2}$ Directorate General of Health Services, Ministry of Health, North Battinah, Oman
}

Received: March 20, 2018

DOI: $10.5430 /$ jnep.v8n12p98
Accepted: July 31, 2018

Online Published: August 20, 2018

\begin{abstract}
Background and objective: Higher education has witnessed significant changes in order to provide quality education that meets the needs of the 21st century. To be in par with international best practices, the foundation program was established to prepare the high school leavers for higher education in Oman, a middle-eastern country. The aims of this study were to (1) assess the relationship between students' high school scores and their cumulative grade point average (CGPA) among the graduates of the nursing program in Oman, and (2) compare the CGPA of the student who attended the general foundation program (GFP) compared to the ones who did not attend the GFP.

Methods: Secondary data analysis approach was used to access the alumni files one year before and one year after the implementation of the GFP. A retrospective approach was used to gather data from the alumni files, which included high school grade, whether the graduates have attended the foundation program or not, their first year Grade point average (GPA), and their CGPA.

Results: Six hundred twenty-seven $(n=627)$ graduates were recruited from two cohorts, one attended the GFP $(n=287 ; 45.8 \%)$ and the others did not attend the GFP $(n=340 ; 54.2 \%)$. Majority of the participants who were included in this study were female graduate $(\mathrm{n}=535 ; 85.3 \%)$. The students who attended the GFP were found to have higher first year GPA and higher CGPA compared to those who did not attend the GFP. High Diploma Scores and First Year GPA were significant predictors of the graduation CGPA of the graduates who did not enroll in the GFP whereas First Year GPA was the main predictors of the CGPA of the graduates who attended the GFP. It was also obvious that the first year GPA showed a higher significant correlation with CGPA among GFP attenders $(r=0.912, p<.01)$ in comparison to non GFP attenders $(r=0.775, p<.01)$.

Conclusions: This study sheds light into the impact of foundation program on the overall students' performance in the nursing program. It significantly reveals that GFP, has a positive impact on the overall CGPA, as it equipped the students with the necessary study skills and increased their English proficiency levels.
\end{abstract}

Key Words: High school grade, General foundation program, Grade point average, Cumulative grade point average, Nursing education

${ }^{*}$ Correspondence: Said A. Alghenaimi; Email: said198@ hotmail.com; Address: Oman College of Health Sciences-South Batinah, Rustaq, Sultanate of Oman. 


\section{INTRODUCTION}

Higher education has witnessed a substantial growth and development in the 21 st century. Thus, it is integral for the higher education in Oman to keep abreast with the requirements that are necessary for knowledge acquisition in higher education. This case is not only applicable to Oman, but also to all Gulf Cooperation Council (GCC) countries. ${ }^{[1-5]}$ In Oman, the Ministry of Higher Education (MOHE) has started considerable reforms to provide quality education. Among these reforms is bridging the gap between high school and higher education. This has been accomplished through many remedies, among which the adoption of the General Foundation Program (GFP), which aims to equip the high-school leavers with the necessary English language skills, computer skills, mathematics, and study skills that are crucial for higher education. The GFP is stipulated following the decision of the Higher Education Council No.13/2008 and the ministerial ordinance No.72/2008. It was declared that all of the higher education institutions (HEIs) in Oman must adopt the GFP standards. At the MOHEIs, unified GFP standards were first applied on the cohort of students who were admitted in the academic year 2011/2012.

On the other hand, the HEIs realized that the GFPs are only a framework to requirements, structure and resources, yet, it does not give a recipe for the best GFP. ${ }^{[1-3]}$ In conjunction with this, AL-Mamari ${ }^{[1]}$ indicated that HEIs are facing many challenges while implementing the GFPs. He attributed these challenges to low proficiency in English for all higher education intakes, entrance requirements, placement test, and resources. Of these problems, the low proficiency in English language was the most challenging to all HEIs. In congruence to AL-Mamri, ${ }^{[1]}$ AL-Mashani ${ }^{[3]}$ identified gap between post-secondary outcome and higher education requirements He further indicated that every year thousands of high school leavers are failing higher education English placement tests where more than $40 \%$ of them were ranked bellow the anticipated standards. In line with this, Carrel and colleges ${ }^{[5]}$ attributed this to the lack of resources that are needed to implement the amended standards. They clearly stated that designing GFP needs expertise, training and faculty in curriculum development.

High school grades are often viewed as an unreliable criterion because of the extraneous factors such as teaching strategy and disparity of resources across different HEIs. ${ }^{[6]}$ Consequently, many countries introduce standardized tests (such as SAT, ACT), which were widely viewed as more valid criteria. However, high school transcript may yield rich information about students' cognitive performance. Yet, the accuracy of the high school score in determining the students' persistence and success in the college remains an open

Published by Sciedu Press question. $^{[7]}$

Belfield and Crosta ${ }^{[7]}$ pointed out that high school grades are useful for predicting many aspects of students' college performance. They also concluded that high school grade has a strong association with their college GPA. However, they reported that high school information is not independently useful beyond high school grades, and collectively it explains less variation in college performance. Some researchers have looked at High school score as predictor to the freshmen grades in college and concluded that high school score is consistently the strongest predictor of the fourth-year college outcomes for all academic disciplines, campuses and freshmen cohorts. ${ }^{[6]}$

\subsection{Significance of the study}

To ensure quality education and to keep abreast with the fast social and linguistic development, GCC countries including Oman, has initiated several reforms to the structure of the higher education systems. One of the most recent reforms in Oman is the establishment of the GFP. ${ }^{[5]}$ The GFP was initiated to prepare and familiarize students to the postsecondary academic life. GFP in Oman consists of one or two years that focus on four areas: language skills, basic mathematics, information technology and general learning skills. ${ }^{[1,2,5]}$ Eighty eight percent $(88 \%)$ of high school graduates in Oman are required to enroll in the foundation program adopted by the HEIs. ${ }^{[1,4,5]}$ Government invested generous resources in the GFP, yet, it remains to be a debatable and controversial issue in the higher education sector in Oman. In the context of Oman, the literature is progressively indicating different and opposing opinions about the significance and efficiency of the foundation program. ${ }^{[1,4]}$ At the Ministry of Health Education Institutes (MOHEIs) a unified GFP was introduced during the academic year 2011-2012.

Education nowadays is faced with numerous challenges starting from changes in the ideology of the current generation and ending with the rapid development in technology. The most successful model in education was the one, which adapts to rapid changes. Worldwide, admission criteria is continuously revised and adapted to meet the need of the higher education and to attract competitive and qualified students. In countries like (USA), high school score is highly significant in determining the students' entrance eligibility to college. According to Cabrera and Burkum, ${ }^{[8]}$ many admission criteria have changed over the years such as the secondary school rank, gender, and race. However, high school grade is still perceived to be an essential admission criterion in USA. Many researchers, even, proved that it is a strong predictor for students' success in the college. ${ }^{[6,9-11]}$ 
MoHEIs heavily rely on the high school scores as indicator for students' admission into the program and students'success. There are even increasing voices that demand raising the level of admission criteria, as part of quality enhancement and producing competitive graduates at the MoHEIs. Conversely, other opinions asserted that interest and motivation play significant role in students' persistence and performance and not the high school score. Thus, scientifically investigating the correlation between the high school score and the students' persistence in college, and performance are significant to inform decision makers.

\subsection{Purpose of the study}

The study seeks to explore the ability of high school scores, and the GFP in predicting the cumulative grade point average (CGPA) of the graduates of the nursing program offered at MOHEIs, Oman. More specifically:

(1) Assessed the ability of high school scores in predicting the CGPA of the graduates of the nursing program in Oman, and

(2) Assessed the difference in the first year GPA, and the CGPA of the students who attended the GFP compared to those who did not attend GFP.

\subsection{Research hypothesis}

In this study we have addressed three hypotheses:

- Hypothesis 1: The students who attended the GFP would have a better first year GPA and a better CGPA compared to the students who did not attend the GFP at the MOHEI;

- Hypothesis 2: There is a significant correlation between high school English score, high school average score, first year GPA and CPGA among the graduates of the nursing program at the MOHEI;

- Hypothesis 3: High school English score, high school average score, first year GPA predict significantly the CPGA among the graduates of the nursing program at the MOHEI.

\section{MeTHODS}

\subsection{Research design}

A retrospective approach was used in this study.

\subsection{Setting}

This study was conducted at the MoHEIs in the Sultanate of Oman. The study delineated the association between high school scores and the CGPA of the graduates of the nursing programs.

\subsection{Sampling}

Secondary data analysis was conducted to compare and contrast the graduates of the nursing program Pre and Post implementation of the GFP. According to Raosoft sample size calculator, ${ }^{[10]}$ the minimum sample size would be 278 participants to achieve a significant statistical result at the $95 \%$ confidence level. All Graduate of the cohort 2013 were included in the pre-GFP; whereas the graduates of the cohort 2015 were included in the Post GFP. Alumni files of the two cohorts were accessed to retrieve data pertaining to the constructs of the study. No personal information was collected apart from the participant's gender, average high school score, English score in High school, first year GPA, and their CGPA. These data was further stratified during the analysis into subgroups in order to perform sophisticated data analysis and comparison between and within the two cohorts.

\subsection{Statistical analysis}

The statistical analysis was carried out using IBM-SPSS version 20. Descriptive statistics, person's correlations, and multiple regressions were used to analyze the data. The normality assumption (for English score, Diploma score, First year GPA and Cumulative GPA) was approximately satisfied through visual inspection as well as skewness values within $\pm 2^{[12,13]}$ and kurtosis values within \pm 3 . $^{[14]}$

\subsection{Ethical considerations}

Prior to the commencement of data collection, permission was sought from the Chairman of the central Research and Ethical Review and approval committee at the Ministry of health headquarter (MH/DGP/R\&S/Proposal_Approved/7/2016).

\section{RESULTS}

\subsection{Participants characteristics}

This study enrolled $(n=627)$ graduates from six nursing institute among the MOHEIs. Among them 340 (54.2\%) did not attend the GFP (cohort 2013) whereas 287 (45.8\%) attended the GFP (cohort 2015). A descriptive statistics of the participants who took part in this study is illustrated in Table 1. As Oman Nursing Institute is the largest nursing institute in Oman, it had the largest number of participants $41.3 \%$ (n $=259$ ) who took part in this study, while the lowest number of participants were from Sur Nursing Institute. Majority of the participants were female graduate $(n=535 ; 85.3 \%)$ whereas the male graduates constituted $14.7 \%(n=92)$.

Table 2 presents a descriptive statistics of the high school scores of the two cohorts before and after the implementation of the GFP. It was noted that students who did not attend 
the foundation program had a higher English scores (Mean $=77.2$ ) compared to those who attended the GFP (Mean $=74.3)$ and the difference was statistically significant $(p=$ .001). Similarly, students who did not attend the foundation program had a higher average score in high school (Mean = 88.0) in comparison to those who attended the GFP (Mean $=84.3)$ and the difference was statistically significant $(p=$ $.001)$.

Table 1. The characteristics of the nursing students by foundation status

\begin{tabular}{|c|c|c|c|c|c|c|c|c|}
\hline \multirow{2}{*}{\multicolumn{2}{|c|}{ Characteristics }} & \multicolumn{4}{|c|}{ Foundation Status } & \multirow{2}{*}{\multicolumn{2}{|c|}{ Total }} & \multirow{3}{*}{ Sig.* } \\
\hline & & \multicolumn{2}{|c|}{ Before $(n=287)$} & \multicolumn{2}{|c|}{ After $(n=340)$} & & & \\
\hline & & Freq. & $\%$ & Freq. & $\%$ & Freq. & $\%$ & \\
\hline \multirow{7}{*}{ Institute } & Dakiliah & 34 & 11.8 & 27 & 7.9 & 61 & 9.7 & \multirow{7}{*}{.001} \\
\hline & Dahirah & 30 & 10.5 & 27 & 7.9 & 57 & 9.1 & \\
\hline & Oman & 133 & 46.3 & 126 & 37.1 & 259 & 41.3 & \\
\hline & Rustaq & 39 & 13.6 & 31 & 9.1 & 70 & 11.2 & \\
\hline & Salalah & 44 & 15.3 & 32 & 9.4 & 76 & 12.1 & \\
\hline & Sur & 7 & 2.4 & 32 & 9.4 & 39 & 6.2 & \\
\hline & Total & 287 & 100.0 & 340 & 100.0 & 627 & 100.0 & \\
\hline \multirow{3}{*}{ Gender } & Female & 243 & 84.7 & 292 & 85.9 & 535 & 85.3 & \multirow{3}{*}{.669} \\
\hline & Male & 44 & 15.3 & 48 & 14.1 & 92 & 14.7 & \\
\hline & Total & 287 & 100.0 & 340 & 100.0 & 627 & 100.0 & \\
\hline
\end{tabular}

* Independent Samples $t$-Test

Table 2. Descriptive statistics for high school scores of the participated nursing students

\begin{tabular}{|c|c|c|c|c|c|}
\hline \multirow[t]{2}{*}{ Variables } & \multicolumn{2}{|c|}{$\begin{array}{l}\text { Before Foundation } \\
\text { (GFP) }\end{array}$} & \multicolumn{2}{|c|}{$\begin{array}{l}\text { After Foundation } \\
\text { (Non-GFP) }\end{array}$} & \multirow[t]{2}{*}{ Sig.* } \\
\hline & Mean & SD & Mean & SD & \\
\hline English Score & 77.2 & 9.3 & 74.3 & 8.8 & 0.001 \\
\hline Average high school Score & 88.0 & 3.8 & 84.3 & 5.6 & 0.001 \\
\hline
\end{tabular}

* Independent Samples $t$-Test

\subsection{Hypothesis testing}

Hypothesis 1: The students who attended the GFP would have a better first year GPA and a better CGPA compared to the students who did not attend the GFP at the MOHEI As illustrated in Table 3, the students who attend the GFP were found to have a higher first year GPA (Mean $=3.0$ ) com- pared to those who did not attend the GFP $($ Mean $=2.5)$ and the difference was statistically significant $(p=.001)$. Furthermore, the students who attended the GFP had a higher CGPA (Mean $=2.8)$ in comparison to those who did not attend the GFP (Mean $=2.6)$ and the difference was statistically significant $(p=.001)$.

Table 3. Descriptive statistics for the GPA of the participated nursing students

\begin{tabular}{|c|c|c|c|c|c|}
\hline \multirow[t]{2}{*}{ Variables } & \multicolumn{2}{|c|}{$\begin{array}{l}\text { Before Foundation } \\
\text { (GFP) }\end{array}$} & \multicolumn{2}{|c|}{$\begin{array}{l}\text { After Foundation } \\
\text { (Non-GFP) }\end{array}$} & \multirow[t]{2}{*}{ Sig.* } \\
\hline & Mean & SD & Mean & SD & \\
\hline First Year GPA & 2.5 & 0.6 & 3.0 & 0.7 & .001 \\
\hline Cumulative GPA & 2.6 & 0.5 & 2.8 & 0.6 & .001 \\
\hline
\end{tabular}

* Independent Samples $t$-Test

Hypothesis 2: There are significant correlations between the High School English Score, High School Average Score, first year GPA and CGPA among the graduates of the nursing program at the $\mathrm{MOHEI}$

Table 4 presents the correlations between the two groups in regards to their high school English scores, their first year

Published by Sciedu Press

GPA, and their CGPA. It was found that the English Scores in high school correlated significantly with First Year GPA $(r=0.215, p<.01)$ and with their CGPA $(r=0.247, p<$ $.01)$ among those didn't attend GFP. Similar result was observed for those attended GFP but with a lower correlation 
coefficient with First Year GPA $(r=0.200, p<.01)$ and with the CGPA $(r=0.223, p<.01)$. Similarly, high school average scores correlated significantly with First Year GPA $(r=0.274, p<.01)$ and with CGPA $(r=0.436, p<.01)$ among those didn't attend GFP. Similar result was observed for those attended GFP but with a higher correlation coef- ficients with First Year GPA $(r=0.420, p<.01)$ and with CGPA $(r=0.428, p<.01)$.

In line with that, it was obvious that the first year GPA shows a higher significant correlation with CGPA among GFP attenders $(r=0.912, p<.01)$ in comparison to non-attenders of the GFP $(r=0.775, p<.01)$.

Table 4. Correlations between Students Scores of Diploma, First year and Graduation year

\begin{tabular}{|c|c|c|c|c|}
\hline \multirow{2}{*}{ Variables } & \multicolumn{2}{|c|}{$\begin{array}{l}\text { Before Foundation } \\
\text { (GFP) }\end{array}$} & \multicolumn{2}{|l|}{$\begin{array}{l}\text { After Foundation } \\
\text { (Non-GFP) }\end{array}$} \\
\hline & First Year GPA & $\begin{array}{l}\text { Graduating } \\
\text { cumulative GPA }\end{array}$ & First Year GPA & $\begin{array}{l}\text { Graduating } \\
\text { cumulative GPA }\end{array}$ \\
\hline English Score & $.215^{* *}$ & $.247 * *$ & $.200 * *$ & $.223 * *$ \\
\hline Average high school Score & $.274 * *$ & $.436 * *$ & $.420 * *$ & $.428 * *$ \\
\hline First Year GPA & 1 & $.775^{* *}$ & 1 & $.912 * *$ \\
\hline
\end{tabular}

** Pearson Correlation is significant at the .01 level.

Hypothesis 3: High school English score, average high school Score, first year GPA predict significantly the CPGA among the graduates of the nursing program at the MOHEI

Table 5 shows the results of the regression analysis to predict factors influencing graduation CGPA. Among students who did not attend the foundation program, High Diploma Scores and First Year GPA were significant predictors of their graduation CGPA. However among students attended the foundation program, First Year GPA was the main predictors of their CGPA along with their gender.

Table 5. Multiple regression models of factors predicting CGPA among students before/after the implementation of the GFP

\begin{tabular}{|c|c|c|c|c|}
\hline \multirow[t]{2}{*}{ Variables in the model } & \multicolumn{2}{|c|}{$\begin{array}{l}\text { Before Foundation } \\
\text { (GFP) }\end{array}$} & \multicolumn{2}{|c|}{$\begin{array}{l}\text { After Foundation } \\
\text { (Non-GFP) }\end{array}$} \\
\hline & $\boldsymbol{\beta}$ & Sig. & $\boldsymbol{\beta}$ & Sig. \\
\hline English Score & 0.002 & 0.294 & 0.002 & 0.215 \\
\hline Average high school Score & 0.035 & 0.001 & 0.004 & 0.179 \\
\hline First Year GPA & 0.646 & 0.001 & 0.771 & 0.001 \\
\hline Gender & 0.062 & 0.291 & -0.101 & 0.013 \\
\hline$R^{2}$ (Adjusted $R^{2}$ ) & \multicolumn{2}{|c|}{$0.66(0.65)$} & \multicolumn{2}{|c|}{$0.84(0.84)$} \\
\hline
\end{tabular}

Table 6 shows the results of the regression analysis to predict factors influencing first year GPA. Among students who did not attend the foundation program, High School Diploma English scores and average scores were significant predictors of their first year GPA. However, among students attended the foundation program, high diploma average scores was the main predictor of their first year GPA along with their gender.

Table 6. Multiple regression model of factors predicting first year GPA among students before/after the GFP implementation

\begin{tabular}{|c|c|c|c|c|}
\hline \multirow[t]{2}{*}{ Variables in the model } & \multicolumn{2}{|c|}{$\begin{array}{l}\text { Before Foundation } \\
\text { (GFP) }\end{array}$} & \multicolumn{2}{|c|}{$\begin{array}{l}\text { After Foundation } \\
\text { (Non-GFP) }\end{array}$} \\
\hline & B & Sig. & B & Sig. \\
\hline English Score & .008 & .024 & .005 & .186 \\
\hline Average high school score & .026 & .009 & .038 & .000 \\
\hline Gender & -.270 & .009 & -.447 & .000 \\
\hline$R^{2}$ (Adjusted $R^{2}$ ) & \multicolumn{2}{|c|}{$0.12(0.11)$} & \multicolumn{2}{|c|}{$0.23(0.23)$} \\
\hline
\end{tabular}




\section{Discussion AND CONCLUSION}

This study premeditated and envisioned to fill the gap in the Omani scholarly community about the impact of foundation program on the overall students' performance in the nursing program at the MOHEIs. It significantly reveals that foundation program has an immense influence on the first-year students' GPA and the overall CGPA. It is obvious that the GFP has equipped students with the studying and language skills capacities (English writing, reading and speaking skills, mathematics and IT) to prepare them for more advanced learning and practical requirements as entailed by the nursing program. The GFP efficaciously lay out a platform for students to build their own knowledge and enacted as a transitional period and turbulent -free landing towards nursing program requirements.

This crucial finding is evidently adding strike to the perpetual debate among the Omani scholarly community about the authenticity and feasibility of the GFP for full one/two year as an introductory phase to the different higher education institutions. Though our finding is not congruent with what AL-Mamri (2012) ${ }^{[1]}$ reported in his study that GFP is not successful in raising students level in English language. Yet this is not the case with our study; which can be explained by the "flexibility" to the GFP content among distinct higher education in Oman. The teaching methodology, resources and infrastructure are predominant aspects that maximize the potential of such program to achieve its genuine purpose Unlike nursing program, for some other programs English usability is not pragmatically accentuated as it is in nursing. In nursing praxis, English is the only media for communication and activating various interdisciplinary descriptions and orders. Thus, the general foundation program becomes a gateway to succeeded in nursing program.

According to some faculties thoughtful insights, stakeholders and planners in the Omani nursing arena, nursing qualities such caring, motivation and communication skills are more important than English score or high school average score. Numbers for them doesn't guarantee the successful accomplishment of nursing program. Yet, this study delineated that English score, high school average score and first year GPA are significant indicators for the overall CGPA. This study, therefore, support the legitimacy of English score, high diploma average score as primary prerequisites for admission to nursing profession in Oman, particularly to nursing profession.

In nursing, the GFP introduced students to the main concepts of writing, speaking and reading, basic mathematics and
IT skills. It also encompasses various activities and practical examples for enhancing students' readings and speaking. Though it comprises merely English skills aspect, but it also introduces them deliberately to the nursing profession in many aspects. The study also underscores the perceptible solidity and constancy of performance among students who attended the GFP in comparison to those did not attend it. Students who didn't attended the GFP exhibit disparities in their performance affected by possibly various environmental and personal factors, yet due to the solid underpinning created by the GFP. The performance of students who attended the GFP was constant toward the completion of the nursing program. In other hand, though English high school score, high school average score, first year GPA were significant predictors of CGPA among all students. This study indicates that first year GPA was the most significant predictor of successful completion of the nursing program for students who attended the GFP. In addition to the first year GPA, the Diploma high school average score was also significant predictor for those did not attend the GFP. This can be explained with the fresh start and the competing skills that the GFP offers to the students. Baporikar and Shah ${ }^{[4]}$ emphasize that there is gap between students' performance in high school and students' performance in college due to weak English academic performance. Yet, from nursing perspective, the conclusion from this study illuminate that appropriate careful consideration of students' previous level and capabilities will augment the successful implication of the GFP.

\section{Limitations}

This study used a retrospective descriptive design, which was limited in the scope to two cohorts of nursing students in Oman. Broader in scope studies are needed to confirm this study finding, which open the door widely to generalize such findings into other disciplines and fields. In addition, one of the biggest limitations in this study is the probability of messing data in certain variable.

\section{ACKNOWLedgements}

We would like to acknowledge the contribution of Mrs. Munira Alblushi, Head of Student's Affair Section at Rustaq Nursing Institute for her contribution in facilitating the data collection. We would like to extend our thanks to all Deans of the nursing programs at the Ministry of Health Educational Institutes, and their medical coordinators who assisted in data collection.

\section{CONFLiCtS OF InTEREST Disclosure}

The authors declare that there is no conflict of interest. 


\section{REFERENCES}

[1] AL-Mamari AS. General foundation program in higher education institution in Oman national standards: implementation and challenges published report. Ministry of Higher Education. Sultanate of Oman. 2012.

[2] Al-Mamari AS. Analyzing results of placement tests in private higher education institutions. Unpublished report. Ministry of higher education, Sultanate of Oman. 2010.

[3] Al-Mashani FM. Aligning general education diploma's outcomes with higher education requirement in the Sultanate of Oman. A thesis submitted as a requirement for an MA in Education. Sultan Qaboos University, Sultanate of Oman. 2011.

[4] Baporikar N, Shah I. Quality of higher education in the 21st centuryA case of Oman. Journal of Educational and Instructional Studies in the World. 2012; 2: 9-18.

[5] Carroll MI, Razvi S, Goodliffe T. Using foundation program academic standards as a quality enhancement Tool. A paper for INQAAHE. 2009.

[6] Geiser SR, Studley UC. Predictive validity and differential impact of the SAT1 and the SAT2at the University of California. Published report, University of California, USA. 2003. Available from: http: //www.cshe.berkeley.edu/sites/default/files/shared /publications/docs/UC\%20and $\% 20$ the $\% 20$ SAT_Geiser.pdf
[7] Belfield C, Crosta I. Predicting success in colleges: The importance of placement test and high school transcripts. Community College Research Center. 2012; 42: 1-8.

[8] Cabrera AF, Burkum KR. College admission criteria in USA: An overview. 2001. Available from: http://www.education.umd. edu/Academics/Faculty/Bios/facData/CHSE/cabrera/Co llegeadmissioncriteriaintheUS.pdf

[9] Johnston MP. Secondary Data Analysis: A Method, of which the time has come. Qualitative and Quantitative Method in Libraries. 2014; 3: 619-626.

[10] Raosoft I. Sample size calculator. 2004. Available from: http: //www.raosoft.com/samplesize.html

[11] Westrick P, Le H, Robbins S, et al. College Performance and Rerension: A meta-analysis of the predictive Validates of ACT Scores, High School Grades and SES. Educational Assessment. 2015; 21: 23-45. https : //doi .org/10.1080/10627197.2015.997614

[12] Gravetter F, Wallnau L. Essentials of Statistics for the Behavioral Sciences. 8th ed. Wadsworth, Belmont, CA. 2014.

[13] Byrne BM. Structural equation modelling with AMOS: Basic concepts, applications, and programming. 2nd ed. New York, NY: Routledge Taylor \& Francis Group. 2010.

[14] Field A. Discovering statistics using SPSS. London: SAGE; 2009. 